\title{
Just a little respect, please
}

B eing treated with a measure of respect is just as important as being taught appropriately, Canadian medical residents asserted in a national survey on the markers of excellent residency programs.

A "collegial, respectful and positive" work environment ranked highest among the spate of characteristics residents identified as crucial to top residency programs in the Canadian Association of Internes and Residents (CAIR) survey, Features of High Quality Residency Programs: A National Resident Perspective.

Some 71 respondents, representing Canada's seven provincial housestaff organizations, identified the following components of the ideal program:

- "A collegial working environment free from intimidation and harassment;

- Adequate transition to practice preparation including appropriate, graded responsibility;

- An appropriate education to service balance;

- Mentorship from the program director and faculty supervisors;

- A curriculum with diverse clinical and procedural exposure;

- Timely assessments with face-toface feedback; and

- A program director who is supportive of resident concerns."

The emphasis on work environment came as "something of a surprise," because reviews of best practices for residency training typically emphasize the ends of such programs over their means, says Dr. Leanne Tran, CAIR member at large and an author of the study. "In Canada, we're pretty good at making sure you come out a medical expert, but the system is changing and I think there's been a paradigm shift to examine and require more of the process to achieving that result."

Residents' perspectives have been largely absent from past national reviews of the training system, says Tran. "It's been a function of an older, top-down approach that past studies have focused on the opinions of staff and consultants."

Across the board, residents expressed a "desire to be treated as future col-

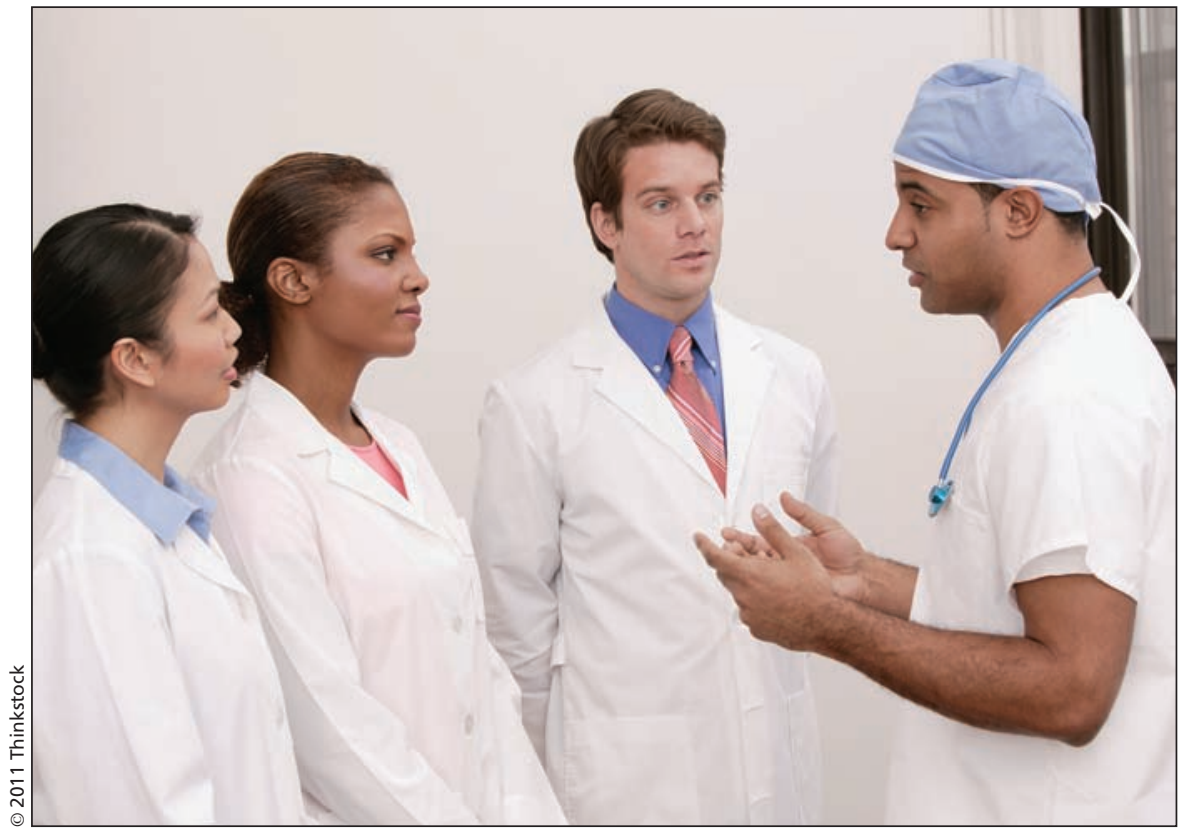

Medical residents say a more collegial attitude is needed in residency programs.

leagues" and therein, delegated "an appropriate level of responsibility and autonomy."

That includes increased exposure to some of the nonmedical competencies that physicians will encounter in their working lives, says Tran. "We're somewhat sheltered in that we don't have all the logistical things down, like billing, how to hire support staff, how to interview for jobs or how to read a contract and know that it's a good one. For the most part, we're not taught these more practical things but they'd make a world of difference in smoothing the transition to practice."

Such programs should also provide residents comprehensive protection against intimidation and harassment, the study states.

"I'd love to say that's not a gap in our current system, but unfortunately intimidation and harassment still happen quite a bit," says Tran. "We need to be realistic about it and admit to ourselves there's a problem."

The hierarchical and stressful nature of medicine unfortunately exacerbates the problem, she adds. While residency programs have mechanisms in place to deal with intimidation and harassment, "there's a lot of pressure on residents not to come forward with any kind of complaint," Tran explains. "It's a difficult problem to address because once you're in a program you're there and it's not easy to move around. Residents feel like they just have to deal with negative interactions because they don't want to affect their training evaluations by coming forward."

CAIR is developing a new policy to identify the behaviors that constitute intimidation and harassment. The organization also hopes to provide residents with practical advice on what to do when they are intimidated or harassed.

It's difficult to gauge the extent of abuse in residency programs across Canada because so few students come forward, while reports are often kept secret in instances where students have complained, she adds. "There's no national database for this kind of thing. Individual provincial health organizations may have some numbers of residents calling in asking for help, but they don't share those statistics."

CAIR conducted the survey to inform an upcoming review of postgraduate medical education being conducted by the Association of Faculties of Medicine of Canada. - Lauren Vogel, $C M A J$

CMAJ 2011. DOI:10.1503/cmaj.109-3850 